\title{
SARS-CoV-2 Reinfection: Two Different Possible Presentations of Disease. Our Experience in a Province of Northern Italy
}

\author{
FabbriNicolò ${ }^{1}$, Greco Salvatore ${ }^{2}$ \\ ${ }^{1}$ Unit of General Surgery, AziendaUnità Sanitaria Locale di Ferrara, Ferrara, Italy \\ ${ }^{2}$ Department of Morphology, Surgery and Experimental Medicine, University of Ferrara, Ferrara, Italy \\ Corresponding Author: FabbriNicolò; n.fabbri@ausl.fe.it \\ *Both authors equally contributed to this article
}

Received 30 September 2020;

Accepted 15 October 2020;

Published 18 October 2020

\begin{abstract}
COVID-19, the disease following SARS-CoV-2 infection, is the most important sanitary concern of the last decade. Many aspects of the infection are still unclear, such as the possibility of the virus to infect patients again after the first contact with the host and recovery.

The current literature does not give fully answers about it; some dedicated reports were published recently even if SARS-CoV-2 reinfection remains an anecdotic event, difficult to confirm because of the intrinsic limitations of disease diagnostic methods.

In this article we report our experience with COVID-19 inpatients who were suspected to be reinfected by SARS-CoV-2. They were both rehospitalized after a period of good health following COVID-19 recovery but they presented at the second hospital admission in two different ways.

The first patient presented at the re-admission without a new viral RNA detection to pharyngeal swab, but with the radiographic findings of disease worsening; the second patient presented instead with a new positive swab but without any radiographic sign of COVID-19 worsening. It is still to determine whether a SARS-CoV-2 reinfection is a common, undiagnosed event, or it is a rare event affecting a very little number of patients. Drawing conclusions from single case reports is hard, but the aim of this little work is to raise clinicians' awareness of a problem that is still far to be solved.
\end{abstract}

Keywords: COVID-19, SARS-CoV-2, reinfection

\section{Introduction}

COVID-19 (COronaVIrus Disease 2019), the infectious disease caused by SARS-CoV-2 (Severe Acute Respiratory Syndrome Coronavirus 2), is the most recent sanitary concern, spreading rapidly worldwide with more than 28 million cases and more than 900.000 deaths in 215 countries as of August, $10^{\text {th }}$.

One of the most interesting aspects of the disease that remains to clarify is about the possibility by SARS-CoV-2 of reinfecting patients.

The current literature was recently enriched with some reports of COVID-19 reinfection: a 33-years old man from Hong Kong was reported to have the first confirmed case of SARS-CoV2 reinfection. The man was infected in March in his home country, probably after being in contact with a colleague who travelled to Hong Kong from London. He developed soon mild symptoms and got tested positive for COVID-19, with a complete clinical recovery and a good health status for a period of more than four months. Meanwhile, he went back to his daily-life habitudes and travelled to Spain for one week for work reasons; when he returned home, he underwent SARS-CoV-2 screening tests, getting positive again with a quite high viral load ${ }^{[1]}$.

The first case of coronavirus reinfection in the United States was documented in Nevada, following similar reports from Hong Kong and in Europe. The patient was found to have the infection by SARS-CoV-2 in April after showing mild disease symptoms. He recovered and tested negative twice, while in June he tested positive again. During this time, he underwent hospitalization (article in preprint).

We report two different cases of suspected reinfections in our province: the first one is about a 75 years old man who required the first hospitalization for COVID-19 symptoms and another hospitalization after a long period of good health, with negative pharyngeal swabs but with the radiographic evidence of a bilateral pneumonia worsening. the second case is about a 47 
years-old man who was diagnosed with a second positive pharyngeal swab to SARS-CoV-2 RNA detection during the second hospitalization required, after a period of good health and negative pharyngeal swabs.

\section{Case Report No. 1}

The following case is about a 75-years old men with a story of smoking (Py 60), hypertension, COPD, CHD in 1993, PTCA in 2006, a biological valve prosthesis positioning in 2007 with prosthetic detachment in 2008 and a new valve positioning, an artery bypass surgery in 2008, an aortic-femoral prosthesis positioning for abdominal aortic aneurysm in 2008, a PM positioning in 2010, atrial fibrillation in anticoagulant therapy with warfarin, chronic kidney disease, chronic venous insufficiency, cholecystectomy, inguinal hernia repair; ceftriaxone and allopurinol allergy.

The patient was admitted twice in January, 2020 to "SS.Annunziata" Hospital in Cento (Fe): the first time during the period 4.01-15.01 while the second time during the period 22.0129.02) due to persistent cough and dyspnea, both related to COPD exacerbation together with his heart failure reacutization.

In March, after a short period of good health he was newly admitted to the same Hospital, Unit of Cardiology, (from 13.03 to 07.04) for a syncopal episode, triggered by a ventricular tachyarrhythmic storm with ICD multiple activations. He was transferred to Hub Hospital in Cona $(\mathrm{Fe})$, to try to ablate the arrhythmic substrate without using any invasive methods and then he was taken to Cento Hospital again to continue his stay. He was discharged on April, $7^{\text {th }}$ and he stayed at home until April, 14.

On April, $14^{\text {th }}$ he was sent back by his General Medicine doctor to Cento Hospital for the sudden onset of cough and dyspnea; a chest CT was performed that showed bilateral ground grass opacities with a strong suspect for interstitial pneumonia. The oro- and nasopharyngeal swab detected SARS-CoV-2 RNA and he was transferred to Lagosanto (Fe) Covid Hospital.

During this stay (14.04-8.05) he was treated with hydroxychloroquine and with antibiotics (azithromycin, levofloxacin and linezolid), high dose diuretics and dobutamine; moreover, he necessitated O2-therapy with non-invasive ventilation (NIV) and a progressive improvement of clinical conditions; the inflammation indexes contextually decreased.

Two consecutive swabs were performed on the $4^{\text {th }}$ and on the $6^{\text {th }}$ of May, a necessary condition for being discharged at home, and they both resulted negative.

After another short period of good health at home, the patient was admitted to Cento Hospital on May, $17^{\text {th }}$ with a severe form of dyspnea with fever. A second chest HRCT was performed and compared to the other one executed during the previous hospital stay: the bilateral interstitial pneumonia was confirmed, with a greater involvement of pulmonary interstitium.

He was transferred to Lagosanto Hospital and diagnosed with heart failure-related respiratory insufficiency. He was treated with non-invasive ventilation (NIV) therapy and tested with two pharyngeal swabs that resulted negative for SARS-CoV-2 RNA detection. His clinical conditions first needed an Intensive Care Unit (ICU) admission while in two days, the patient was discharged from ICU and admitted to the Cardiology department of Cento Hospital.

During this last stay, he was tested twice for SARS-CoV-2 with a suspect of reinfection, but the two pharyngeal swabs performed resulted negative to viral RNA detection (May, $19^{\text {th }}$ and $26^{\text {th }}$ ). On June 6 , due to a multi organ failure because of heart failure reacutization the patient died in Cento Hospital.

Tab1:Summarizes all hospital stays, clinical presentations and radiographic characteristics of the chest HRCT and CT performed.

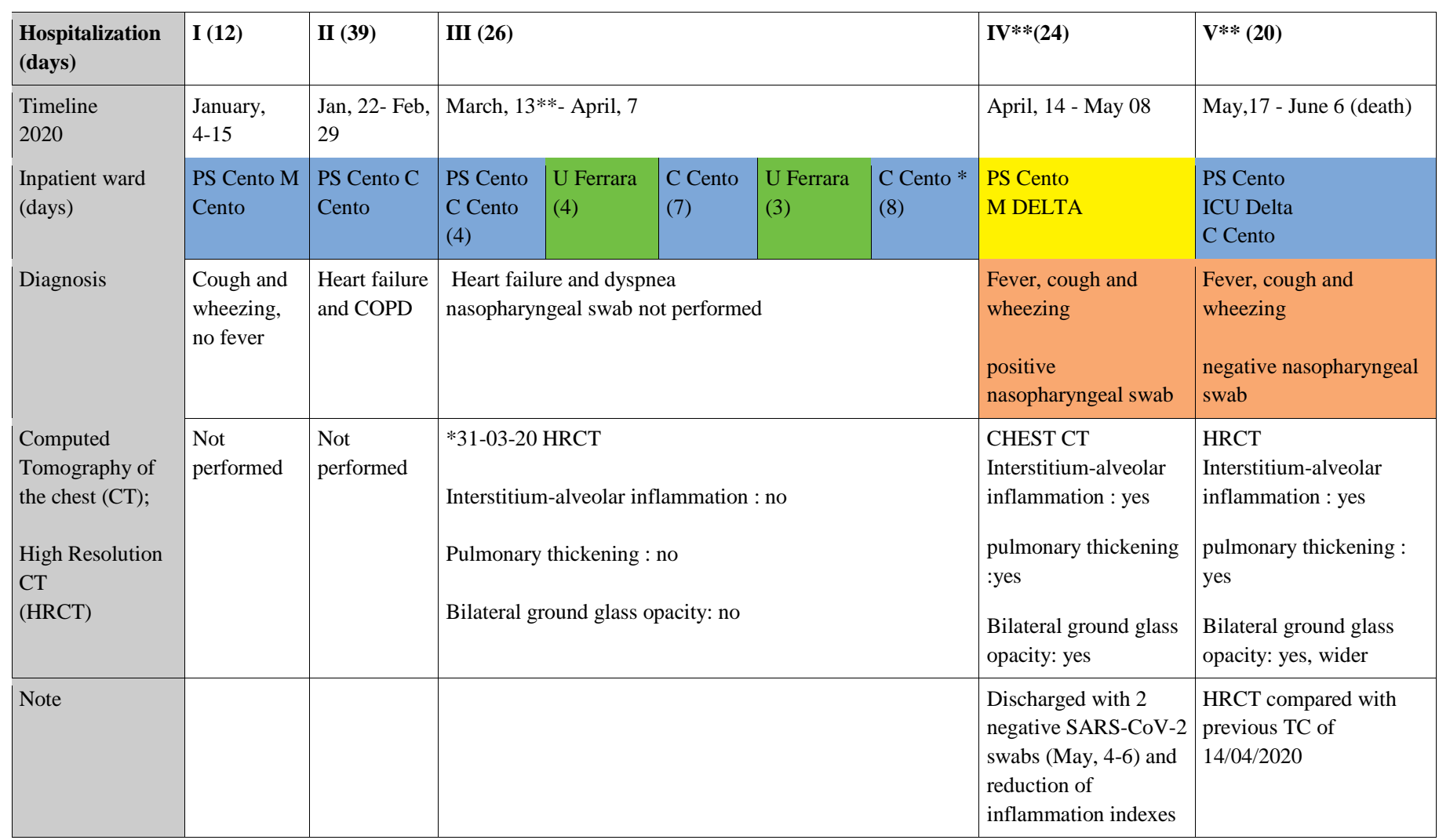

Tab. 1: Time line Patient 1.

M: Medicine Ward; U: Coronary Care Unit; C: Cardiology, PS: Emergency Service; ICU: Intensive Care Unit. Blue tab: COVID-free Hospital; Green tab: Mixed Hospital, Yellow Tab: COVID-Hospital; * First Chest CT performed; **refers to declaration of COVID-19 pandemic 


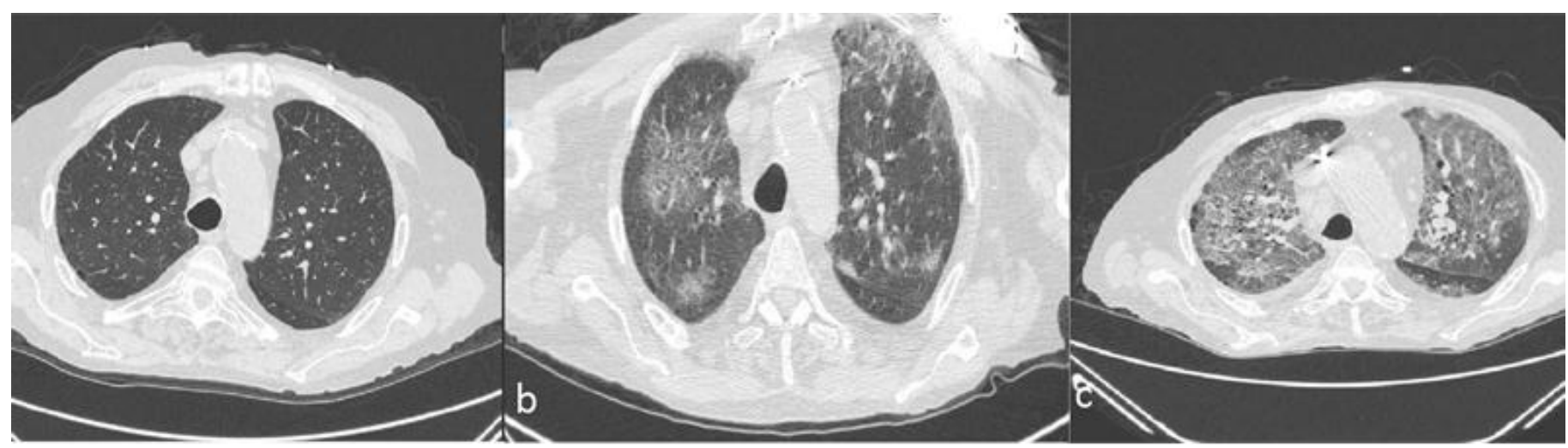

Fig.1: Computerized Chest Tomography scans of the first patient: a) first chest HRCT executed on March, 30; b) chest CT of April, 14; c) second chest HRCT executed on May, 1

\section{Case report no. 2}

The second case is about a 47-years old man from Philippines with a story of remitted acute lymphocytic leukaemia and of internal jugular vein thrombosis; piperacillin/tazobactam and Imatinib allergy.

He was admitted to "S.Anna" Hospital in Cona (Fe), the Hub Hospital of Ferrara's province, on March 1, with fever, pharyngodynia, vomiting and diarrhoea. He was tested with a chest HRCT that documented an apical pulmonary thickening and some consolidated areas in the lower lobes, bilaterally.

For the sudden onset of severe hypotension, tachypnea and hyperpyrexia he was admitted to ICU, where he was treated with high-flow oxygen therapy, amine support, broad-spectrum antibiotic therapy (meropenem, linezolid, azithromycin, then modified with clindamycin and daptomycin for the finding of otomastoiditis) and antimycotic therapy (fluconazole). On the $7^{\text {th }}$ of March, he was admitted to the Internal Medicine department.

Here, he shared the hospital room with another patient who was later tested positive for SARS-CoV-2 infection: one pharyngeal swab detected viral RNA and he was transferred to the pulmonology department that was dedicated to COVID-19 inpatients. He was treated with hydroxychloroquine and antiretroviral therapy (ritonavir-darunavir). On March 27, he was discharged at home with the obligation of isolation until the finding of two consecutively negative pharyngeal swabs to viral RNA detection. He was tested with a second chest HRCT that showed some improvements in the small airways damage and confirmed the presence of consolidated areas in the lower lobes of both lungs. On May 15 and 16, he was tested negative for SARS-CoV-2, ending home isolation.

After some months of good health, on September 8 he was admitted to the local first aid with persistent headache and vomiting. For this reason a brain $\mathrm{CT}$ was performed, without any pathologic finding and he was tested with a pharyngeal swab that resulted negative for SARS-CoV-2 RNA detection. He was admitted to Haematology department where a maxillofacial bones CT was performed to deepen his clinical case and he was diagnosed with vasomotor rhinitis: therefore, he was treated with antibiotic (ceftriaxone) and steroid therapy. At his $7^{\text {th }}$ day of stay, according to the regional new guidelines concerning the clinical approach to COVID-19, he was tested with another pharyngeal swab that resulted positive (on September 15). After this finding, he was transferred to the Pulmonology department, where he remained asymptomatic during the whole hospital stay and he was treated with prophylactic low molecular weight heparin (LMWH) and azythromycin. A third chest HRCT was performed on September 16 , but it was almost fully comparable to the previous one.

On September 19, he was discharged at Lagosanto (Fe) Hospital for completing the therapeutic process, until a full recovery.

\begin{tabular}{|c|c|c|c|c|c|c|}
\hline $\begin{array}{l}\text { Hospitalization } \\
\text { (days) }\end{array}$ & \multicolumn{4}{|l|}{ I (76) } & \multicolumn{2}{|l|}{ II (11) } \\
\hline $\begin{array}{l}\text { Timeline } \\
2020\end{array}$ & \multicolumn{4}{|l|}{ March, 1-15 } & \multicolumn{2}{|l|}{ September, 8-19 } \\
\hline $\begin{array}{l}\text { Inpatient ward } \\
\text { (days) }\end{array}$ & $\begin{array}{l}\text { ID Ferrara } \\
\text { (4) }\end{array}$ & $\begin{array}{l}\text { ICU Ferrara } \\
\text { (3) }\end{array}$ & $\begin{array}{l}\text { ID Ferrara ** } \\
\text { (19) }\end{array}$ & $\begin{array}{l}\text { M Delta } \\
(50)\end{array}$ & $\begin{array}{l}\text { E Ferrara } \\
(8)\end{array}$ & $\begin{array}{l}\text { P Ferrara } \\
15-19(5)\end{array}$ \\
\hline Diagnosis & $\begin{array}{l}\text { fever, sore-throat and } \\
\text { abdominal pain }\end{array}$ & $\begin{array}{l}\text { severe } \\
\text { hypotension, } \\
\text { tachypnea and } \\
\text { hyperpyrexia }\end{array}$ & $\begin{array}{l}\text { In-hospital contact } \\
\text { with a COVID } \\
\text { patient: first } \\
\text { positive } \\
\text { nasopharyngeal } \\
\text { swab }\end{array}$ & $\begin{array}{l}\text { May 15-16: two negative } \\
\text { nasopharyngeal swab tests }\end{array}$ & $\begin{array}{l}\text { Headache and vomiting } \\
\text { negative } \\
\text { nasoharyngeal swab }\end{array}$ & $\begin{array}{l}\text { 15-09: second } \\
\text { positive } \\
\text { nasopharyngeal } \\
\text { swab } \\
\text { No } \\
\text { symptomatology }\end{array}$ \\
\hline $\begin{array}{l}\text { Computed } \\
\text { Tomography of } \\
\text { the chest (CT); } \\
\text { High Resolution } \\
\text { CT } \\
\text { (HRCT) }\end{array}$ & $\begin{array}{l}* 03-03 \text { HRTC } \\
\text { interstitium-alveolar } \\
\text { inflammation : Yes } \\
\text { pulmonary thickening } \\
\text { :Yes } \\
\text { Bilateral ground glass } \\
\text { opacity: Yes }\end{array}$ & & & $\begin{array}{l}15-05 \\
\text { HRTC } \\
\text { interstitium-alveolar } \\
\text { inflammation : No } \\
\text { pulmonary thickening : } \\
\text { No } \\
\text { Bilateral ground glass } \\
\text { opacity: No }\end{array}$ & $\begin{array}{l}16-09 \\
\text { HRTC } \\
\text { interstitium-alveolar infle } \\
\text { pulmonary thickening : } \mathrm{N} \\
\text { Bilateral ground glass op }\end{array}$ & $\begin{array}{l}\text { hation : No } \\
\text { y: No }\end{array}$ \\
\hline
\end{tabular}




\begin{tabular}{|c|c|c|c|c|}
\hline Note & $\begin{array}{l}\text { HRTC: pericardial } \\
\text { effusion } \\
\text { Therapy: } \\
\text {-Clindamycin, } \\
\text { - Meropenem, } \\
\text { - Daptomycin } \\
\text { Acute Lymphoblastic } \\
\text { Leukemia in remission } \\
\text { with Dasatinib }\end{array}$ & $\begin{array}{l}\text { Therapy: } \\
\text { - Linezolid } \\
\text { - Doxiciclin } \\
\text { - Ritonavir- } \\
\text { Darunavir }\end{array}$ & $\begin{array}{l}\text { Swab performed for } \\
\text { regional surveillance } \\
\text { protocol } \\
\text { Therapy: } \\
\text { - Azithromycin } \\
\text { - Heparins }\end{array}$ & $\begin{array}{l}\text { September 23- } \\
\text { 24: two negative } \\
\text { nasopharyngeal } \\
\text { swab tests }\end{array}$ \\
\hline
\end{tabular}

Tab. 2: Timeline of Patient n.2.

ID: Infectious Diseases Department; ICU: Intensive Care Unit; E: Hematology Ward; P: Pulmonology Department .Blue tab: COVID-free Hospital; Green tab: Mixed Hospital, Yellow Tab: COVID-Hospital; * First Chest CT performed; **refers to declaration of Covid-19 pandemic

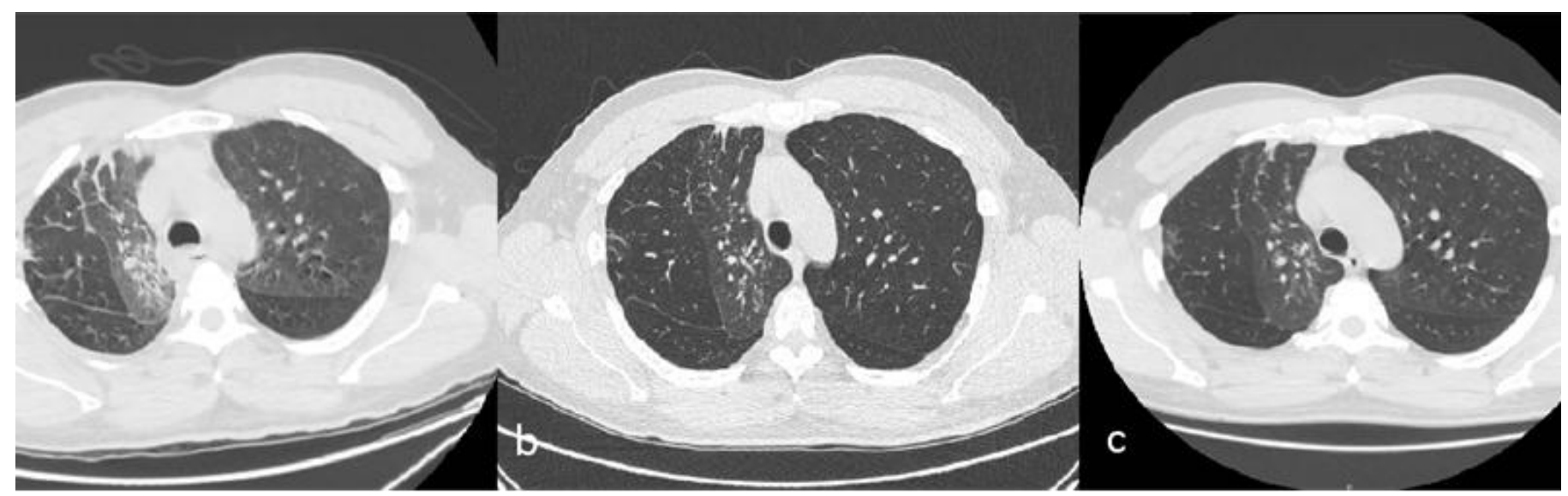

Fig.2: Computerized Chest Tomography scans of the second patient: a) first chest HRCT executed on March 2; b) second chest CT of May 12; c) third chest HRCT of September 16

\section{Discussion}

SARS-CoV-2 reinfection still remains an exceptional event, difficult to confirm with the standard exams usually performed.

In May, 2020, Sayak Roy ${ }^{[2]}$ affirmed this: "Reinfection with SARS-CoV-2 seems unlikely taking into consideration our knowledge on viral neutralizing antibody duration from past respiratory illnesses, the type of specimen collection and technical errors associated with each component of swab testing, the methods used before discharging these patients, the presence of fecal viral RNA without evidence of replication-competent virus in fecal swabs, and finally the reassurance from the animal study. But till we have to take into consideration the probability of genetic mutations as observed rather than reinfection by the same strain."

Recently, the British Medical Journal (BMJ) published the world's first proven case of reinfection, thanks to the comparison of viral RNA sequences. This case was reported by some scientists in Hong Kong: the man got infected with SARS-CoV-2 in March while being in London; he was tested for SARS-CoV-2 infection due to mild respiratory symptoms, resulting positive to oro- and naso-pharyngeal swab RNA detection. After being discharged, he went back home to Hong Kong in healthy conditions, but some months after he newly got infected and he was found to have high viral load: in this case he developed a severe form of COVID-19 (article in pre-printing).

It is to underline how it is important to be sure about the negativity of detections. The intrinsic limitations of swabs do not always allow being fully sure of a negative viral RNA detection, first of all because of the false negative tests expected: by definition, only $5 \%$ of patients with viral load at the limit of detection are expected to be missed ( 1 in 20 patients). This percentage grows for patients with viral loads below this threshold [4].

The proper methods of swab collection have been discussed by Petruzzi et al. Upper respiratory tract samples like these should be collected within a few days of onset of symptoms as the highest titers of RNA are reached within 7-10 days of symptom onset and declines thereafter. The virus can be isolated from various sites of the body, and the concentration varies from 1 day to another, resulting in variation of positivity ${ }^{[5]}$.

The highest percentage of positive detections rate from bronchoalveolar lavage (BAL) specimen (93\%), followed by sputum (72\%), nasal swab (63\%), fibro-bronchoscope brush biopsy (46\%), pharyngeal swab (32\%), feces $(29 \%)$, and blood $(1 \%)^{[2]}$.

Another concern is the reactivation of cases that got the infection, then recovered and got isolated at home or in another healthcare facility. This issue was brought to public attention as on April $13^{\text {th }}$, when South Korea government reported that 116 recovered cases of SARS-CoV-2 infection were found positive again ${ }^{[3]}$.

In Italy, the first SARS-CoV-2 infections were identified during the last March and, in our province, the first cases were mainly localized in the territory of Cento $(\mathrm{Fe})$.

The events' timeline examined in our case report no.1(Tab.1) and the incubation period of SARS CoV-2 (that seems to be ranging from 2 to 14 days with a median time of 7,8 days and a mean time of 8,3 days $^{[6]}$ ) would suggest that the first infection had place in the territory of Cento $(\mathrm{Fe})$, where the patients lived, or with less probability during his stay in the Cardiology department in Cento Hospital (30.03-07.04).

Before being discharged at home after his first positive oroand naso-pharyngeal swab, the man got two consecutive negative swabs, with a net decrease of the inflammation indexes (CRP 2,76 $\mathrm{mg} / \mathrm{dl}$, Procalcitonin $0,19 \mathrm{pg} / \mathrm{ml}$, White Blood Cells $15 \times 10^{3} / \mathrm{mmc}$ ). 
On May 17, the patient went back to Cento First Aid with persistent cough and dyspnea. He was tested again with an oro- and naso-pharyngeal swab for SARS-CoV-2 RNA detection with negative result. A Chest HRCT was performed (Fig.3) and compared to the other one executed on the 30th of March (Fig.1) and to Chest CT of the $14^{\text {th }}$ of April (Fig.2): the pulmonary interstitial involvement was wider as well as the pulmonary thickening.

He needed admission to ICU in Lagosanto Hospital and, following an improvement in clinical conditions, he was transferred to Cardiology department in Cento Hospital. On June 6, the patient died in Cento Hospital due to the consequences of heart failure reacutization. Neither a bronchoalveolar lavage, nor a viral RNA sequencing were performed during these hospitalizations:therefore we could not certify whether a colonization by SARS-CoV-2 and this clinical case remains, for all these reasons, a suspect.

The case report no.2 is somehow different from the other one: the patient was first admitted to the Hub Hospital of the territory of Ferrara on March,1 with fever, pharyngodynia and gastrointestinal symptoms. The chest HRCT, executed the day after, documented an apical pulmonary thickening with consolidated areas in the lower lobes. After his clinical conditions rapidly worsened, he was admitted to ICU and treated with highflow oxygen therapy, amine support, antifungals and antibiotics until March 7, when he was admitted to our Internal Medicine department.

During that phase of epidemics, the Italian clinicians used to consider the epidemiologic criteria for isolating patients suspected to have SARS-CoV-2 infection: this patient did not meet this condition, for the missing contact with infected patients. He was not isolated and shared his hospital room with another patient who was later tested positive for COVID-19. He was tested with a pharyngeal swab to viral RNA detection that resulted positive; he was transferred to COVID Pulmonology department and got treated with hydroxychloroquine and antivirals. After being discharged at home with the obligation of isolation, he was tested with a second chest HRCT that evidenced some improvements: on May 15 and 16 he was tested negative for SARS-CoV-2 RNA detection with two consecutively negative pharyngeal swabs, ending home isolation and returning to his daily life activities.

The period of good health following the hospitalization was longer than that of the first patient but on September 9 he was hospitalized again with headache and vomiting. After some days from hospital admission he was tested positive again for SARSCoV-2 and he was admitted to the Pulmonology department and a new chest HRCT was performed with no new findings. His clinical conditions were good during the whole duration of stay, until he was transferred to Lagosanto $(\mathrm{Fe})$ Hospital for completing the therapeutic process.

It is still unclear whether suspected cases like this effectively depend on an insufficient immunity response, incapable of limiting the disease: in this case, it would be plausible to think that the disease flare is a consequence of the incomplete response by the immunity system and of the lack of efficient specific antibodies.

The recent discover of at least six strains of SARS-CoV-2 [7], however, could lead to a new possible explanation of this kind of cases: in particular, the immunization against the first virus encountered would not be sufficient to defeat a second, different strain of the virus itself, taking to new symptoms and to a new need for an immunity response.
As for the case report no.1, the viral RNA sequencing or the serological dosage of IgG and IgM for SARS-CoV-2 could have helped us dating the onset of the disease, allowing us to make more precise hypothesis. A bronchoalveolar lavage could have helped excluding, instead, the persistence of infection in the lower airways since the first viral RNA detection with a pharyngeal swab.

Without these kinds of analysis, it is impossible to confirm the diagnosis of reinfection by SARS CoV-2; on the other hand, the two chest HRCTs performed have shown wide difference in the pulmonary involvement between the first and the second, hypothetic, viral infection.

The case report no. 2 was characterized by a second SARSCoV-2 RNA detection to pharyngeal swab after a long period since the first one. During this time, the patient first recovered and returned to his daily life, remaining asymptomatic to COVID-19, then he was newly admitted to COVID Hospital with headache and vomiting. The chest HRCTs performed during the two hospitalizations go in a diametrically opposite direction with respect to the symptomatology: the pulmonary involvement noticed in the last chest HRCT was, in fact, comparable to that executed during the first hospitalization.

This novel coronavirus has strongly changed the way of approaching medicine in the last months: the need for new findings about SARS-CoV-2 infection and COVID-19 is day by day higher.

Our hope is that these two case reports could represent a new cue for deepening some aspects of the infection, especially when recurring in the story of a patient.

\section{Conclusion}

In this article, we reported our experience with two patients suspected with SARS-CoV-2 reinfection. The two cases are different from each other even if they could represent the two "sides of the same coin": on one hand, the first patient was found to have very different radiographic images from the first hospital stay to the last one, but with a persistent negativity of pharyngeal swabs, despite his symptoms. On the other hand, the second patient was tested positive to SARS-CoV-2 again after a long period of a good health after his first positive swab and full recovery (meant as two consecutively negative pharyngeal swabs).

SARS-CoV-2 reinfection remains for the moment an anecdotic event and the current literature concerning reinfections is still poor of case reports. It is still unclear whether the finding of a new positive pharyngeal swab to viral RNA, after two or more negative swabs, represents a new infection by the "first" virus, whether it represents the possible new infection by a different strain of SARS-CoV-2 itself, or whether it is a consequence of the intrinsic limitations of swab methods.

Performing appropriate analysis such as a viral RNA sequencing or a serologic dosage of specific antibodies, in case of a strong suspect of reinfection, could definitely help clinicians accept or refuse this hypothesis.

The main goal of this article is to raise general awareness about the possibility of finding patients reinfected by SARS-CoV2 , although we understand that it is still very difficult to discriminate the best tests that could prove the existence of a reinfection by this virus.

\section{Ethics approval and consent to participate}

All patients hospitalized into the two COVID-hospitals of Ferrara territory received appropriate informations regarding possible future studies. If necessary, they all gave approval and consent to 
the study; in case it was not possible to receive any verbal consent by the patient himself, it was received by the patient's relatives.

\section{Data Availability}

All data are property of Arcispedale "S.Anna", in Cona (Fe), "SS.Annunziata" Hospital in Cento (Fe) and Ospedaledel Delta in Lagosanto (Fe). Laboratory, anamnestic and instrumental data can be found in the electronic registers of the aforementioned hospitals.

\section{Authors' contributions}

Both authors analyzed and interpreted the patients data and chose the most representative CT scans as for the two case reports.

The article was written by SG and revised critically by NF for important intellectual content. Both authors agree with the statements of the article.

\section{Conflicts of Interest}

The authors have no conflict of interest to declare.

\section{Funding Statement}

No financial support from any public or private institution was performed for this research.

\section{Acknowledgments}

None

\section{References}

[1] Jane Parry Covid-19: Hong Kong scientists report first confirmed case of reinfection BMJ 2020;370:m3340 http://dx.doi.org/10.1136/bmj.m3340 Published: 26 August 2020

[2] Sayak Roy COVID-19 Reinfection: Myth or Truth? SN Compr. Clin. Med. 22 May 2020 https://doi.org/10.1007/s42399-020-00335-8

[3] JavadAlizargar Letter to the Editor: Risk of reactivation or reinfection of novel coronavirus (COVID-19) Research Center for Healthcare Industry Innovation, National Taipei University of Nursing and Health Sciences, Taipei City 112, Taiwan Journal of the Formosan Medical Association (2020) 119, 1123, 15 April 2020

[4] RamyArnaout, Rose A. Lee, Ghee Rye Lee, Cody Callahan, Christina F. Yen, Kenneth P. Smith, RohitArora, and James E. Kirbya, SARS-CoV2 Testing: The Limit of Detection Matters Version 1.bioRxiv. Preprint. 2020 Jun 4. doi: 10.1101/2020.06.02.131144

[5] Gerardo Petruzzi MD, Armando De Virgilio MD, PhDBarbara Pichi MDFrancesco Mazzola MDJacopo Zocchi MDGiuseppe Mercante MDGiuseppe Spriano MDRaul Pellini MD. COVID-19: Nasal and oropharyngeal swab. https://doi.org/10.1002/hed.26212

[6] Jing Qin, Chong You2, Qiushi Lin, Taojun Hu, Shicheng $\mathrm{Yu}$ Xiao-Hua Zhou, Estimation of incubation period distribution of COVID-19 using disease onset forward time: A novel cross-sectional and forward follow-up study. DOI: 10.1126/sciadv.abc1202

[7] Daniele Mercatelli and Federico M. Giorgi, Geographic and Genomic Distribution of SARS-CoV-2 Mutations. Front. Microbiol., 22 July 2020 | https://doi.org/10.3389/fmicb.2020.01800 